\title{
Application of Microcontroller and Color Sensor for Soil Parameter Measurement and Control
}

\author{
Yuvraj V. Parkale, PhD \\ Department of Electronics and Telecommunication Engineering, \\ SVPM's College of Engineering, Malegaon (Bk), Baramati, (Affiliated to Savitribai Phule Pune University), \\ Maharashtra, India
}

\begin{abstract}
In early days, there is a problem of growth of crops due to the lack of fertilizers. Either there will be excess of fertilizers or lack of fertilizers. Due to this there is serious problem of growth. To overcome these problems this paper proposes a NPK measurement of soil and automatic soil fertilizer dispensing robot. The proposed system measures nitrogen, phosphorus, and potassium from soil and the required amount of deficient fertilizers are dispensed in the soil. The Nitrogen is responsible for growing of leafs, and phosphorous is used for growth of root. The proposed system will reduce the overall cost and increases the efficiency of the system.
\end{abstract}

\section{Keywords}

NPK, Soil measurement, robot, microcontroller etc.

\section{INTRODUCTION}

The quality of plants and crops growth depends greatly on physical and chemical properties of soil that is on soil composition: minerals and organic matter, water, gases like oxygen and carbon dioxide, and living being (primarily micro-organisms such as fungi and bacteria). Soil is not only a support system, but also a nutritive source that supplies plants with water and nutrients. Each plant needs a particular soil composition, in which it can better express its potential growth. For this reason, a correct balance in soil components is fundamental to ensure an optimal crop growth. The most important elements for plant growth are nitrogen $(\mathrm{N})$, phosphorus $(\mathrm{P})$ and potassium $(\mathrm{K})$ : for this reason they are called essential nutrient elements or macronutrients. These elements are usually added to the soil by fertilization. Other elements, the so called microelements, are generally present in sufficient quantities in the soil and the plants need them in smaller doses. Milwaukee NPK Soil Test Kit a lows to measure the concentration of the three elements $\mathrm{N}, \mathrm{P}, \mathrm{K}$ in a soil sample. A table at the end of this manual shows $\mathrm{N}, \mathrm{P}$ and $\mathrm{K}$ requirements of common crops and plants.

The proposed work is all about the agricultural development in the farm. At that time it is found that there are some good growth plants while some are unable to growth well. So why not to develop such a system which known perfectly about growth of plants in farm. Also an investigations were carried in agricultural industries. In such industries it is found that there are some instruments or machines for measurement of useful fertilizers in soil. But such measurements are not taken out in practical use in farm. However, the fact remains that most of us do not undergo regular measurement of soil due to the reasons of inconvenient timing and ease of accessibility.
An existing system consists of measurement of NPK testing kit $\&$ them one has to manually feed the fertilizer in the farm for the particular crop [1, 2, and 3]. The existing system have some limitations such as these system have time consuming processes, these system have higher cost, measurement can be done in laboratory only, the whole process is manual and thus not applicable for direct use in the farm [4-9].

The aim of this proposed work is to design and develop easy and reliable system, which could be effectively used for practical use of instrument using robotic system instead of the conventional system used in industry [1].

This would be user friendly, cost effective and efficient in terms of analysis, data storage and maintenance. The present work successfully enables subjects to conduct soil measurement tests fully with the help of dispensing robot without any additional accessories. The NPK tests could be conducted regularly so as to facilitate the early measurement of soil at farm or any place and time convenient to the user.

The paper is organized as follows: Section 2 presents the proposed system design. Section 3 elaborate the result and Section 4 gives the conclusions.

\section{PROPOSED SYSTEM DESIGN}

The figure 1 shows the block diagram of the proposed system consists of blocks such as: microcontroller, color sensor, RS232, LCD, actuator driver, relay and solenoid valves.

In the proposed system, the measurement of NPK will be done by color sensor \& NPK measurement kit. According to the color, the required fertilizers will be dispensed out for the reservoir provided on the robot. The robot will automatically dispense the same in the farm, it will save time \& hence more area will be covered.

\section{RESULT}

The figure 2 shows the system flowchart of the proposed system. The color sensor will sense the NPK values from the soil. These input values are compared with standard reference values by the microcontroller. If the input values and standard values are same then the robot will move forward. Otherwise, the solenoid valve will dispense the required amount of deficient fertilizers in the soil. Table 1 shows the number of soil samples taken and their measured NPK parameters. It is observed that many soil samples are deficient with fertilizers. Thus, the robot will automatically dispense the deficient fertilizers into the soil. 


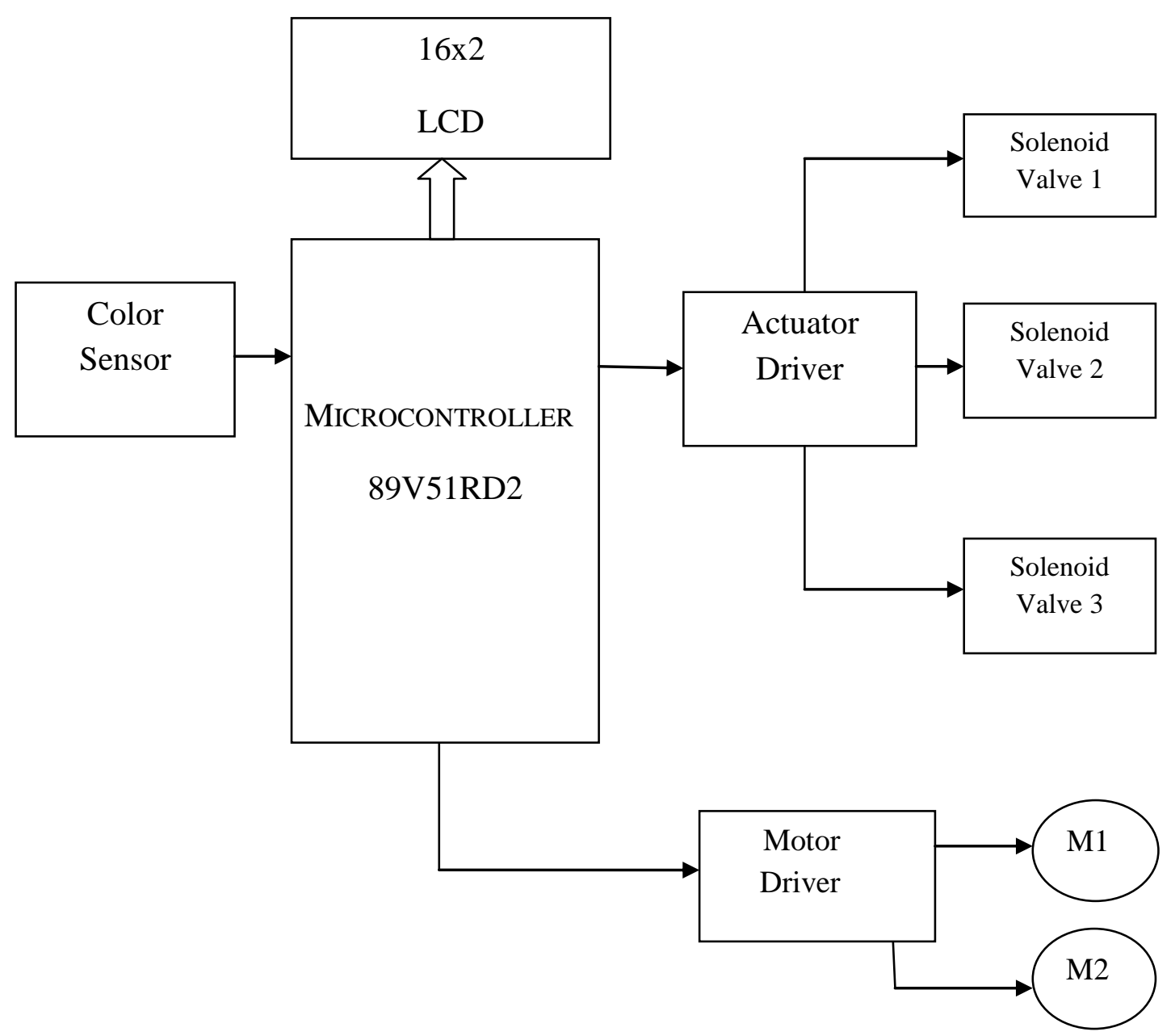

Fig 1: block diagram of the proposed system

Table 1. Soil sample collection and analysis

\begin{tabular}{|c|c|c|c|c|c|c|c|c|c|c|}
\hline Fertilizer & S1 & S2 & S3 & S4 & S5 & S6 & S7 & S8 & S9 & S10 \\
\hline $\mathbf{N}$ & Low & Normal & Normal & Low & High & High & Normal & High & High & Low \\
\hline $\mathbf{P}$ & Normal & Low & Normal & High & High & Low & High & Low & Normal & Low \\
\hline $\mathbf{K}$ & High & High & Normal & High & High & Low & Normal & High & Low & Low \\
\hline
\end{tabular}

Where, S-Soil sample 


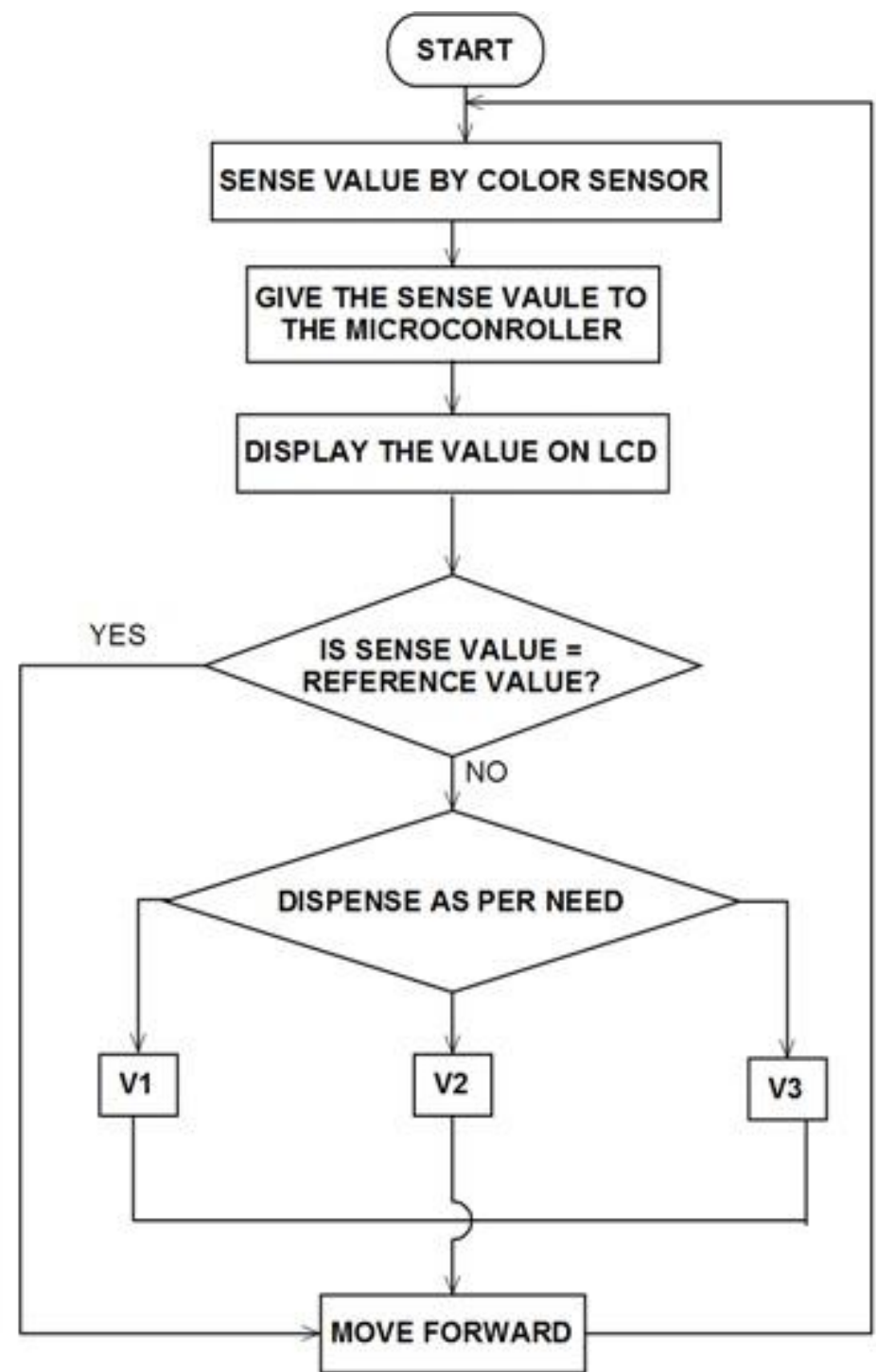

Fig 2: Flowchart of the Proposed System

\section{CONCLUSION}

The proposed work reduces the time of execution, measurement and testing. The system cost is reduced and higher efficiency is achieved. This work will be very much useful for performing standard measurement tests in farms, garden or the agricultural workplace and also in research and teaching in the field of agricultural. The proposed work is user friendly, cost effective and efficient in terms of analysis, data storage and maintenance compared to the conventional farming.

The system is reliable, faithful, uninterrupted, economical and user friendly. A larger area can be covered and NPK fertilizers in soil can be controlled effectively. The system combined the low power, low cost, small size sensors. The sensor and dispensing mechanism controls the NPK contents in soil.

\section{REFERENCES}

[1] N. Singh and A. Shaligram, "D. NPK Measurement in Soil and Automatic Soil Fertilizer Dispensing Robot," International Journal of Engineering Research \& Technology, vol. 3, no. 7, pp. 635-637, 2014.

[2] Akriti Jain, Abizer Saify, Vandana Kate, "Prediction of Nutrients (N, P, K) in soil using Colour Sensor
(TCS3200)", International Journal of Innovative Technology and Exploring Engineering (IJITEE) ISSN: 2278-3075, Volume-9 Issue-3, January 2020

[3] R. L. Yadav, B. S. Dwivedi, K. Prasad, O. K. Tomar, N. J. Shurpali, P.S. Pandey, "Yield Trends And Changes In Soil Organic-C And Available Npk In A Long-Term Rice-Wheat System Under Integrated Use Of Manures And Fertilizers. Field Crops Res.", 2000, 68: 219-246.

[4] J. Shen, R. Li, F. Zhang, J. Fan, C. Tang, Z. Rengel, "Crop Yields, Soil Fertility And Phosphorus Fractions In Response To Long-Term Fertilization Under The Rice Monoculture System On A Calcareous Soil Field Crops Res. ", 2004, 86: 225-238.

[5] R. L. Yadav, D. S. Yadav, R. M. Singh, A. Kumar," Long Term Effects of Inorganic Fertilizer Inputs on Crop Productivity in A Rice-Wheat Cropping system. Nutr. Cycl. Agroecosystem", 1998, 51: 193-200.

[6] L. G. Wang, J. J. Qiu, W. J. Li, "Study On The Dynamics Of Soil Respiration In The Field Of Summer Corn In Huanghuaihai Region In China. Soil Fertility", 2002, 6: 13-17 (In Chinese).

[7] K. Wu, X. Q. Xie, "Time Series Analysis of Applied 
International Journal of Computer Applications (0975 - 8887)

Volume 183 - No. 23, September 2021

Fertilizer and Its Positive and Negative Effects on Agricultural Development in the Huang-Huai-Hai Plain. Agro-Environ. Protect”, 2002, 21(6): 516-518, 523

[8] Nanjing Agricultural University. "Agrochemical Analysis of Soil (In Chinese). Agricultural Press",
Beijing, 1981, 386pp.

[9] Y. S. Wang and Y. H. Wang, "Quick Measurement of $\mathrm{Ch} 4, \mathrm{Co} 2$ and N2emissions from a Short-Plant Ecosystem. Adv. Atmos. Sci”. , 2003Tavel, P. 2007 Modeling and Simulation Design. AK Peters Ltd. 